\title{
Radiographic measurement of total lung capacity in acute asthma
}

\author{
MITCHELL S ROTHSTEIN, MELVIN N ZELEFSKY, PETER Q EICHACKER, \\ DANIEL J RUDOLPH, M HENRY WILLIAMS Jr
}

From the Pulmonary Division, Department of Medicine, and Department of Radiology, Albert Einstein College of Medicine, and the Bronx Municipal Hospital Center, New York, USA

ABSTRACT The thoracic cage appears to be large during attacks of asthma. Lung volume measurements by body plethysmography and helium dilution have suggested that total lung capacity $\vec{O}$ may be increased during an acute attack of asthma, but doubt has been cast on the accuracy of theseo measurements in the presence of airflow obstruction. The change in total lung capacity has therefore ${ }_{-}$ been investigated during and after an acute attack of severe asthma in 32 patients by a radiographic $\subset$ technique. There was a small decrease $(0.29 \mathrm{l})$ in mean total lung capacity between admission and ${ }_{\bar{\sigma}}$ follow up, though a quarter of the subjects showed a slight increase. There was no correlation between $\vec{\varphi}$ change in total lung capacity and change in expiratory flow rates, arterial carbon dioxide tension on ${ }_{0}^{\circ}$ admission, body mass index, and length of stay in hospital. Our findings agree with previous reports of a decrease in total lung capacity with improving airway obstruction, but the changes were small and inconsistent.

\section{Introduction}

Since the report of Woolcock and Read in 1966 it has been commonly stated that total lung capacity (TLC) is increased during an acute attack of asthma. ${ }^{1}$ Measurements of TLC by both plethysmography and helium dilution, however, have been inconsistent, and plethysmographic volumes may be falsely raised in patients with airway obstruction. ${ }^{1-4}$ Total lung capacity can also be calculated by geometric measurements of the chest radiograph. ${ }^{5}$ The values obtained by the method of Barnhard, ${ }^{5}$ later modified by Loyd et $a l,{ }^{6}$ have been shown to correlate with plethysmographic values of TLC in normal subjects and in patients with various pulmonary disorders. The method should not be subject to the errors inherent in the helium dilution and the plethysmographic techniques in patients with asthma. Miller and Offord compared the Barnhard-Loyd technique with another radiological method of estimating total lung capacity and found that the two methods gave similar results.? Although the study by Rodenstein ${ }^{8}$ suggests that the computer assisted method of Pierce yields more

\footnotetext{
Address for reprint requests: Dr $\mathbf{M}$ Henry Williams Jr, Bronx Municipal Hospital Center, Van Etten Hospital, Pelham Parkway and Eastchester Road, Bronx, New York 10461, USA.

Accepted 17 March 1989
}

accurate results than the Barnhard-Loyd method both methods compared favourably with plethys mographic measurements. Harris et al showed good agreement between radiological measurement (deter mined by both a planimetric method and the elliptical method of Barnhard and Loyd) and plethysmographie measurement of total lung capacity. ${ }^{10}$ We have therefore used the Loyd modification of the Barnhare method.

The purpose of the present study was to determine whether TLC, as measured by the radiologica method, is increased in acute asthma.

\section{Methods}

Thirty two asthmatic patients admitted to the Brons Municipal Hospital Center from April 1985 ta November 1986 participated in the study. Criteria foß admission to the study included a diagnosis of asthma on admission with no other documented illness and $x$ peak expiratory flow (PEF) of $180 \mathrm{l} / \mathrm{min}$ or less. At the time of admission measurements of PEF (Wright pea flow meter), forced expiratory volume in one second $\left(F_{1}\right)$, and forced vital capacity (FVC; Breopi spirometer model 2400 ) were carried out. In each cas $\bar{\Phi}$ the best of at least two good efforts was selected. Aftef improvement following treatment these measurements were repeated. Twenty six of the 3 
patients had arterial blood gas measurements on admission (Instrumentation Laboratory, 1306 TM blood gas analyser).

Radiographic lung volume was measured by Barnhard's method ${ }^{5}$ as modified by Loyd ${ }^{6}$ at the time of the expiratory flow measurements both on admission and at follow up. A trained technician instructed the patients to inspire maximally and hold their breath while the film was exposed. All measurements from the radiographs were made "blind" without knowledge of clinical information. The reproducibility of our technique was tested by making repeated measurements from the same film on 10 patients. The mean difference in TLC between the measurements was less than $3 \%$ (range 0-6\%). In three normal subjects values of TLC from serial chest radiographs differed by less than $5 \%$ in each case. The relative weight index, the actual weight/predicted weight, was determined as described by Bruce et al." Predicted values for total lung capacity and $\mathrm{FEV}_{1}$ were determined according to equations of Kory et $a l^{12}$ and Knudson et al. ${ }^{13}$

\section{ANALYSIS}

Change in radiographic TLC during the hospital admission was related to 13 variables: relative weight index, arterial $\mathrm{PCO}_{2}$, radiographic TLC at presentation/predicted TLC, PEF (initial), change in PEF, $\mathrm{FEV}_{1}$ (initial), change in $\mathrm{FEV}_{1}, \mathrm{FEV}_{1}$ (initial)/predic-

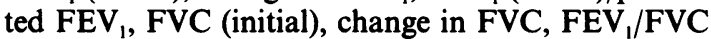
(initial), $\mathrm{FEV}_{1} \%$ change, and time between studies (days). Data are presented as means with standard deviations in parentheses. Differences in mean values were evaluated by Student's two tailed paired $t$ test and correlations were assessed by linear regression.

\section{Results}

The 27 women and five men in the study had an average age of $40 \cdot 2$ (range 20-57) years. The mean time between initial and follow up studies was 7.5 days (78\% within eight days). The mean (SD) arterial $\mathrm{PCO}_{2}$ at admission was $5.0(1.2) \mathrm{kPa}$. The mean (SD) PEF at presentation was $130(25.6) \mathrm{l} / \mathrm{min}$ and had improved by $150(71.9) \mathrm{l} / \mathrm{min}$ at follow up. FVC improved from 1.49 to $2.68(0.63) 1$, and mean (SD) $\mathrm{FEV}_{1} / \mathrm{VC}$ was 48.4 $(12 \cdot 4)$ and improved to $67 \cdot 4(16 \cdot 3)$. There was a small but significant decrease in mean radiographic TLC between presentation $(4.7(1.2) 1)$ and follow up $(4.4$ $(1 \cdot 2) l ; p=0.05)$. Eight patients showed an increase in radiographic total lung capacity at follow up.

The changes in radiographic TLC and PEF for 26 of the 32 patients studied are shown in the figure. Six of the patients were unable to perform a PEF manoeuvre at the time of the TLC measurement because of excessive coughing. There was no correlation between change in radiographic TLC and any of the 13

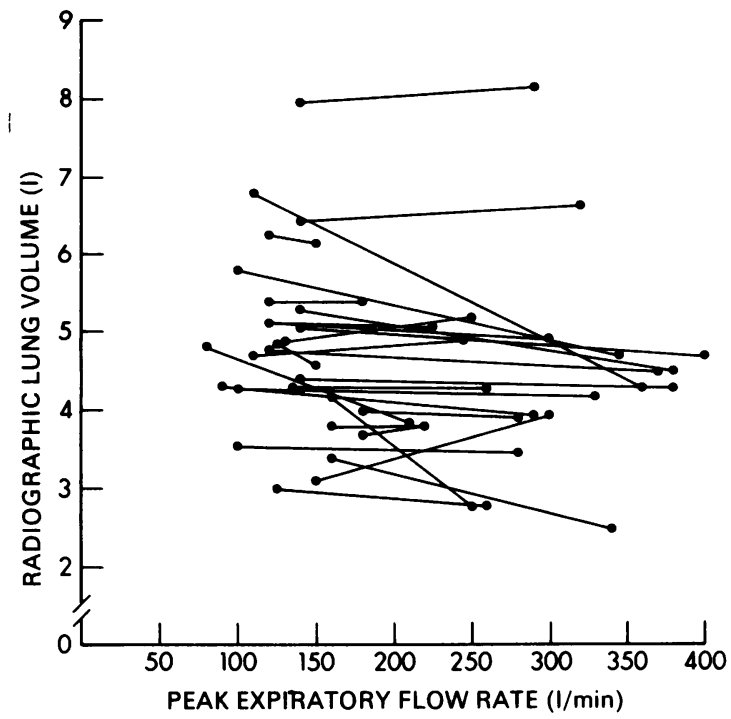

Change in radiographic lung volume at total lung capacity and change in peak expiratory flow rate (PEF) for 26 of the 32 patients studied (in six $P E F$ was not measured at the time of admission).

variables studied. There was no correlation between the increase in TLC and these same variables in the eight patients who showed an increase in TLC during the study.

\section{Discussion}

Our study, like others, has shown a decrease in total lung capacity as asthma improved, though none of our patients showed the large changes that have been noted by those who have used the helium dilution and plethysmographic techniques. Helium dilution has been found to give inconsistent results in airway obstruction, resulting in both overestimation and underestimation of TLC. ${ }^{214}$

Plethysmography has been shown to give falsely raised values for TLC in patients with airways obstruction, because mouth pressure underestimates alveolar pressure owing to loss of pressure between the mouth and the alveoli. Using oesophageal pressure to measure pleural pressure changes, Rodenstein and Stanescu found that TLC was overestimated by plethysmography and underestimated by helium dilution in patients with chronic airflow obstruction ${ }^{3}$; they found a similar overestimation of TLC by plethysmography in asthmatic patients with acute induced bronchoconstriction. ${ }^{4}$ This artefactual increase in TLC in asthma as measured by plethysmography has been confirmed by other investigators. ${ }^{15}$ Brown and coworkers suggested that underestimation of alveolar 
pressure may be secondary to non-homogeneous pleural pressure swings, being greater over areas of closed airways. ${ }^{16}$ Panting has also been shown to affect lung volume determinations. ${ }^{17}$

Radiographic measurement of TLC was found to correlate well with the results of helium dilution and plethysmography in 33 asthmatic patients with mild airways obstruction $\left(\mathrm{FEV}_{1} 59 \%\right.$ predicted). ${ }^{18}$ In another study four asthmatic patients identified as having an increased TLC by helium dilution during an exacerbation were shown not to have a significant increase in radiographic TLC. ${ }^{2}$ In our study there was a small $(290 \mathrm{ml})$ but significant decrease in mean TLC during remission from an acute exacerbation of asthma, though $25 \%$ of the patients showed an increase in TLC during remission.

It has been suggested that a reduction in TLC, by reducing lung recoil and traction on airways, might result in failure of expiratory flow rates to increase as . asthma improves. ${ }^{1}$ In our study all patients showed an increase in expiratory flow regardless of a fall in TLC and there was no relation between change in flow rate and change in TLC. We also found no correlation between body weight index and change in lung volume and could not therefore ascribe the lack of increase in TLC in some of our patients with acute asthma to the restrictive effects of obesity.

Our study group may have represented an atypical cross section of patients with asthma as they had an average age of 40 years, most had a lifelong history of asthma, and all required admission to hospital and parenteral treatment. Conceivably a younger population with a more explosive onset and recovery might have shown larger volume changes and a closer relation between improving flow rates and decreasing lung volumes.

We would like to acknowledge the technical support of Dr Sung Park and the secretarial assistance of Sylvia Kringdon and Dawn Hellwinkel.

\section{References}

1 Woolcock AJ, Read J. Lung volumes in exacerbations of asthma. Am J Med 1966;41:259-73.

2 Zelefsky MN, Swain BK. The nature of the increased lung volume in asthma. Br J Dis Chest 1971;65:39-43.

3 Rodenstein DO, Stanescu DC. Reassessment of lung volume measurement by helium dilution and by body plethysmography in chronic air-flow obstruction. $\mathrm{Am}$ Rev Respir Dis 1982;126:1040-4.

4 Stanescu DC, Rodenstein DO, Cauberghs M, Van de Woestijne KP. Failure of body plethysmograph in bronchial asthma. J Appl Physiol 1982;52:939-48.

5 Barnhard J, Pierce JA, Joyce JW, Bates JH. Roentgenographic determination of total lung capacity. A new method evaluated in health, emphysema, and congestive heart failure. Am J Med 1960;28:51-60.

6 Loyd HM, String ST, Dubois AB. Radiographic and plethysmographic determination of total lung capacity. Radiology 1966;86:7-14.

7 Miller RD, Offord KP. Roentgenologic determination of total lung capacity. Mayo Clin Proc 1980;55:694-9.

8 Rodenstein DO, Sopwith T, Denison DM, Stanescu DC. Re-evaluation of the radiographic methods or measurement of total lung capacity. Bull Eur Physiopathol Respir 1985;21:521-5.

9 Pierce RJ, Brown DJ, Holmes M, Cumming G, Denison DM. Estimation of lung volumes from chest radiographs using shape information. Thorax 1979;34:726-34.

10 Harris TR, Pratt PC, Kilburn KH. Total lung capacity measured by roentgenograms. Am J Med 1971;50: 756-63.

11 Bruce KA, Kusmi F, Hosmer D. Maximal oxygen intake and normographic assessment of functional aerobic impairment in cardiovascular disease. Am Heart $J$ 1973;85:546-60.

12 Kory RC, Callahan R, Boren HG, Syner JC. The Veterans Administration-Army cooperative study of pulmonary function. I: Clinical spirometry in normal man. Am J Med 1961;30:243-58.

13 Knudson RJ, Slatin RC, Lebowitz MD, Burrows B. The maximal expiratory flow volume curve normal standards variability and effects of age. Am Rev Respir Dis 1976;113:587-600.

14 Woolcock AJ, Rebuck AS, Cade JF, Read J. Lung volume changes in asthma measured concurrently by two methods. Am Rev Respir Dis 1971;104:703-9.

15 Shore S, Milic-Emili J, Martin JG. Reassessment of body plethysmographic technique for the measurement of thoracic gas volume in asthmatics. Am Rev Respir Dis 1982;126:515-20.

16 Brown R, Ingram RH Jr., McFadden ER Jr. Problems in the plethysmographic assessment of changes in total lung capacity in asthma. Am Rev Respir Dis 1978;118:685-92.

17 Habib MP, Engel LA. Influence of panting technique on the plethysmographic measurement of thoracic gas volume. Am Rev Respir Dis 1978;117:265-71.

18 Marmorstein BL, Ciancluzzi FD. Planimetric measurement of total lung capacity in asthma. Chest 1974;66:378-81. 